\title{
AKAP4 Positive
}

National Cancer Institute

\section{Source}

National Cancer Institute. AKAP4 Positive. NCI Thesaurus. Code C142842.

An indication that AKAP4 expression has been detected in a sample. 